Vol. 9(8), pp. 230-236, 29 February, 2015

DOI: 10.5897/AJ PP2015. 4266

Artic le Number: 34EFD5E51346

ISSN 1996-0816

Copyright $\odot 2015$

Author(s) retain the copyright of this a ricle

http:// www.academicjoumals.org/AJPP

\title{
Evaluation of anti-inflammatory activity of the bark of Eysenhardtia polystachya in experimental animal models
}

\author{
Rosa Martha Perez Gutierrez
}

Laboratory of Research on Natural Products, School of Chemical Engineering and Extractive Industries del IPN Unidad Profesional Adolfo Lopez Mateos, Zacatenco, del IPN. Av. Instituto Politécnico Nacional S/N. CP.07508, México.

Received 1 January, 2015; Accepted 16 February, 2015

\begin{abstract}
The bark of Eysenhardtia polystachya, has been used in Mexican folk medicine for treatment of antiinflammatory diseases. This study aimed to investigate the anti-inflammatory activity, on various animal models using carrageenan-induced oedema, cotton pellets-induced granuloma, induction of acute inflammation by histamine, croton oil induced ear oedema, activity of myeloperoxidase, adjuvantinduced arthritis, quantification of tumor necrosis factors alpha (TNF $\alpha$ ), interleukin-1 beta (IL-1 $\beta$ ), prostaglandin E2 $\left(\mathrm{PGE}_{2}\right)$ and leukotriene $\mathrm{B} 4\left(\mathrm{LTB}_{4}\right)$ in arthritic rat. Methanol extract (PAM) was also performed by assessing the activities of lipoxygenase and xanthine-oxidase. Our data indicate that PAM exhibited significant anti-inflammatory activity in all the trials of paw and ear oedema induced exhibiting also anti-arthritic activity. PAM could also markedly inhibit production of proinflammatory cytokines, especially TNF $\alpha$, IL-1 $\beta, \mathrm{PGE}_{2}$ and $\mathrm{LTB}_{4}$. These effects resulted in an attenuation of the inflammatory cytokines and ultimately suppression of the oedema. The extract also inhibited lipoxygenase and xanthine-oxidase. It was seen that PAM is effective on chronic inflammation and acute inflammation.
\end{abstract}

Key words: Eysenhardtia polystachya, anti-inflammatory, cytokines, inflammation.

\section{INTRODUCTION}

The tree Eysenhardtia polystachya, (Ortega) Sarg, belonging to the Leguminosae family, is known as "palo azul" and has widely been used for the treatment of nephrolithiasis, as a blood depurative, diuretic and antirheumatic and bladder disorders developed with diabetes (Perez et al., 1998). Phytochemical studies indicate that E. polystachya contains polyphenols (Burns et al., 1984). In another study, isoflavans displayed moderate cytotoxic activity against KB cell lines (Alvarez et al., 1999). The methanolic extract of branches displayed hypoglycaemic activity (Alvarez and Delgado, 1999a). In another report, methanolic bark extract was further separated by column chromatography, yielding four known substances: (-)-epicatechin, (+)-afzelechin, eriodictyol, (+)-quercetin-3-O-p-D-galactopyranoside, all of which showed scavenging properties against free 
radical 1,1-diphenyl-2-picrylhydrazyl (DPPH) (NarvaezMastache et al., 2008). In previous studies, the hypoglycemic, antioxidant potential and advanced glycation endproducts (AGEs) inhibition capacity of the methanol-water extract from the bark of $E$. polystachya in vitro assays, and also using diabetes-induced oxidative damage in the liver, kidney and pancreas was evaluated (Gutierrez and Baez, 2014). This study was undertaken to evaluate the anti-inflammatory potential of plant extracts using various animal models.

\section{MATERIALS AND METHODS}

Plant

Bark of E. polystacya was collected in Ixmiquilpan, Hidalgo, México in June 2011. Voucher specimens (4532) were deposited in the Herbario de la ENEP-Iztacala UNAM for further reference.

\section{Animals}

Male Wistar rats weighing 150 to $200 \mathrm{~g}$ were obtained from the Laboratory Animal Services Center, Escuela Nacional de Ciencias Biologicas-IPN, Mexico. All animals were acclimated for 1 week under $12 \mathrm{~h}$ light and $12 \mathrm{~h}$ dark cycle at room temperature of $22 \pm 1^{\circ} \mathrm{C}$. Chow diet and water were provided ad libitum. Experiments reported in this study were carried out following the guidelines stated in Principles of Laboratory Animal Care (National Institute of Health Publication (NIH) 85-23, revised 1985 and the Mexican Official Normativity (NOM-062-Z00-1999)). All animals' procedures were performed in accordance with the recommendations for the care and use of laboratory animals (756/lab/ENCB).

\section{Preparation of plant extracts}

A total of $1000 \mathrm{~g}$ of the bark of $E$. polystachya were dried and powdered in a mechanical grinder. The ground material was extracted with $5 \mathrm{~L}$ of hexane (PAH), chloroform (PAC) and methanol (PAM) consecutively using a soxhlet apparatus. These extracts were filtered and concentrated by a rotary vacuum evaporator and kept in a vacuum desiccator for complete solvent removal.

\section{Carrageenan-induced rat paw oedema}

The rats were divided into 5 groups $(n=6)$. Acute inflammation was produced by the subplantar administration of $0.1 \mathrm{ml}$ of $1 \%$ carrageenan in normal saline in the right paw of the rats. The different groups were treated with PAH, PAC and PAM (50, 100, and $200 \mathrm{mg} / \mathrm{kg}$, p.o.), indomethacin (10 mg/kg, p.o.) and control vehicle were administered orally. The paw volume was measured at 0 and $3 \mathrm{~h}$ after carrageenan injection using plethysmometer. The animals were pretreated with the extracts $1 \mathrm{~h}$ before the administration of carrageenan. The extracts and the standard used for this study were prepared in the same manner as mentioned earlier. The ratio of the anti-inflammatory effect of the extracts was calculated by the following equation: anti-inflammatory activity (\%) = $(1-D / C) \times 100$, where $D$ represents the percentage difference in paw volume after extract was administered to the rats, and $\mathrm{C}$ represents the percentage difference of volume in the control groups (Washiyama et al., 2009).

\section{Cotton pellets-induced granuloma}

The rats were divided into four groups $(n=6)$. After shaving, the rats were anaesthetized and $10 \mathrm{mg}$ of sterile cotton pellets were inserted, one in each axilla. The extracts $(50,100,200 \mathrm{mg} / \mathrm{kg}$, p.o.) and indomethacin (10 mg/kg, p.o.) and control vehicle were administered orally for 7 consecutive days from the day of cotton pellet implantation. The animals were anaesthetized on the eighth day and cotton pellets were removed surgically and made free from extraneous tissues. The pellets were incubated at $37^{\circ} \mathrm{C}$ for $24 \mathrm{~h}$ and dried at $60^{\circ} \mathrm{C}$ to constant weight. Increment in the dry weight of the pellets was taken as measure of granuloma formation (Gupta et al., 2003).

\section{Induction of acute inflammation in rat hind paws by histamine}

The anti-inflammatory activity of the extract was measured with phlogistic agents (namely, histamine, 5-HT) which act as mediator of inflammation. Acute inflammation in the hind paws was induced by the subcutaneous injection of $0.05 \mathrm{ml}$ of the prepared solutions of histamine $(1 \%)$ into the right hind paws of the rats. The left hind paws without injection were used as control. The volumes $(\mathrm{ml})$ of both hind paws of rat were measured using a plethysmometer (Plethysmometer 7150, UGO Basile, Italy) at $1 \mathrm{~h}$ before induction and $0.5,1,2,3,4,6 \mathrm{~h}$ after induction of the inflammation. The increased volumes (paw edema) of the right hind paws of rats were calculated by the following equation: the increased rate $(\%)=(B-$ A) $/ A \times 100$, where $A$ and $B$ represent the paw volumes before induction of inflammation and at different time points after the induction, respectively. Extracts $(100,50,25,12.5 \mathrm{mg} / \mathrm{kg}$ ) or vehicle were intraperitoneally administrated $10 \mathrm{~min}$ prior to histamine injection. The reference drug, indomethacin $(10 \mathrm{mg} / \mathrm{kg})$, was orally administered $1 \mathrm{~h}$ prior to histamine injection (Jing-Rong et al., 2008).

\section{Croton oil induced ear edema in mouse}

The edema was induced by application of $20 \mu \mathrm{l}$ of croton oil (200 $\mu \mathrm{g})$ diluted in a solution of acetone/water $(7: 3)$ to the inner surface of the mouse's left ear. The right ear received only the vehicle (20 $\mu \mathrm{l})$. Immediately after injecting the phlogistic agent, in the groups of treated animals we applied $20 \mu \mathrm{l}$ of the total extract $(1.25,2.5,5.0$, $7.5 \mathrm{mg}$ ) to the left ear. In the control group, $20 \mu \mathrm{l}$ of the vehicle was applied to the left ear. After $6 \mathrm{~h}$, the animals were killed, and the ears were sectioned in discs $6.0 \mathrm{~mm}$ in diameter and weighed $(\mathrm{mg})$ in an analytical balance. The percentage of inhibition of edema was determined (Van Arman, 1974).

\section{Activity of myeloperoxidase (MPO)}

The MPO activity was evaluated in the supernatant of homogenates of the

ear

sections (controls and those treated with crude extract, $5.0 \mathrm{mg}$; or indomethacin, $1.0 \mathrm{mg}$ ), according to the technique described by Bradley el al. (1982). The ear tissue was placed in $50 \mathrm{mM}$ potassium phosphate buffer, $\mathrm{pH} 6.0$, containing $0.5 \%$ hexadeciltrimethylammonium bromide (Sigma, $1 \mathrm{ml} / 50 \mathrm{mg}$ of tissue) in a Potter homogenizer. The homogenate was vortex-mixed and centrifuged for $5.0 \mathrm{~min}$ at $2500 \mathrm{rpm}$. Ten microliters of the supernatant thus obtained was added to a 96well microplate, in triplicate, followed by addition of $200 \mu \mathrm{l}$ of a buffer solution containing O-dianisidine dihydrochloride (Sigma, $16.7 \mathrm{mg}$ ), bidistilled water $(90 \mathrm{ml})$, potassium phosphate buffer (10 $\mathrm{ml}$ ) and $1 \% \mathrm{H}_{2} \mathrm{O}_{2}(50 \mu \mathrm{l})$. The enzyme activity was determined by measuring the absorbancy $(460 \mathrm{~nm})$. 
Table 1. Effect of the PAM extract on carrageenan induced paw oedema and on cotton-pellet induced granuloma in rats.

\begin{tabular}{lccccc}
\hline \multirow{2}{*}{ Treatment } & \multirow{2}{*}{ Dose $\mathbf{~ m g / k g}$} & \multicolumn{4}{c}{ Paw edema (Percentage inhibition) at different time intervals } \\
\cline { 2 - 6 } & & $\mathbf{1}$ & $\mathbf{2}$ & $\mathbf{3}$ & $\mathbf{4}$ \\
\hline Carrageenan control & 0 & 0 & 0 & 0 & 0 \\
PAM & 50 & $12.44 \pm 2.22^{\mathrm{b}}$ & $19.41 \pm 6.12^{\mathrm{b}}$ & $23.07 \pm 6.43^{\mathrm{b}}$ & $34.61 \pm 7.38^{\mathrm{b}}$ \\
PAM & 100 & $28.31 \pm 4.52^{\mathrm{a}}$ & $36.26 \pm 8.58^{\mathrm{a}}$ & $48.45 \pm 4.67^{\mathrm{a}}$ & $61.53 \pm 8.10^{\mathrm{a}}$ \\
PAM & 200 & $37.62 \pm 5.31^{\mathrm{a}}$ & $48.73 \pm 7.52^{\mathrm{a}}$ & $60.32 \pm 7.28^{\mathrm{a}}$ & $73.26 \pm 7.31^{\mathrm{a}}$ \\
Indomethacin & 10 & $52.23 \pm 6.23^{\mathrm{b}}$ & $57.62 \pm 3.49^{\mathrm{b}}$ & $73.21 \pm 5.52^{\mathrm{a}}$ & $78.43 \pm 6.28^{\mathrm{a}}$ \\
STD & 10 & $21.47 \pm 7.21^{\mathrm{a}}$ & $39.46 \pm 4.72^{\mathrm{a}}$ & $55.43 \pm 6.78^{\mathrm{a}}$ & $68.12 \pm 4.21^{\mathrm{a}}$ \\
\hline
\end{tabular}

Values represent mean \pm SEM $(n=8)$. One way ANOVA followed by Dunnet's multiple comparison test. ${ }^{a} p<0.05,{ }^{b} p<0.01$, statistically significant relative to control. Diclofenac sodium (STD).

\section{Adjuvant-induced developing arthritis in rat}

Adjuvant arthritis was induced in rat by the subplantar injection of $0.02 \mathrm{ml}$ freshly prepared suspension $(5.0 \mathrm{mg} / \mathrm{ml})$ of steam killed Mycobacterium tuberculosis (Difco, USA) prepared in liquid paraffin in the left hind foot pad. The volume of the injected (primary inflanmmatory response) (Arrigoni-Martelli and Bramm, 1975) and uninjected (secondary immune mediated response) paws were quantitated on day 13 after the adjuvant injection. The volume of the injected as well as uninjected paws was measured by a volume differential meter model 7101, Ugo Basile, Italy and the effect determined on day 13.

Quantification of tumor necrosis factors alpha (TNF $\alpha$ ), interleukin-1 beta (IL-1 $\beta)$, prostaglandin E2 (PGE $)$ and leukotriene B4 $\left(\mathrm{LTB}_{4}\right)$ in serum samples of arthritic rat

Samples of the serum obtained on day 14 from different groups of animals were prepared for the analysis of cytokine mediators. TNFa, IL-1 $\beta, \mathrm{PGE}_{2}$ and $\mathrm{LTB}_{4}$ were estimated using commercially available kits based on sandwich and competitive enzyme-linked immunosorbent assay (ELISA) technique (R\&D Systems, MN, USA) according to the manufacturer's instructions. All cytokine concentrations were carried out by means of colorimetric measurement at $450 \mathrm{~nm}$ on an ELISA plate reader (Multiskan, Thermo Electron Corporation, MA, USA) by interpolation from a standard curve.

\section{Enzyme inhibition assay}

\section{Xanthine oxidase $(X O)$ inhibition assay}

The xanthine oxidase inhibition activity was assayed on a spectrophometer according to a method previously described by Owen and Timothy (1999). The assay mixture consisted of $150 \mu \mathrm{l}$ of phosphate buffer $(0.066 \mathrm{M}$; pH 7.5), $50 \mu$ of extract solution (1 $\mathrm{mg} / \mathrm{ml}$ in phosphate buffer), and $50 \mu$ of enzyme solution $(0.28$ $\mathrm{U} / \mathrm{ml})$. After pre-ineubation at room temperature $\left(25^{\circ} \mathrm{C}\right)$ for $3 \mathrm{~min}$, the reaction was initiated by addition of $250 \mu$ l of substrate solution (Xanthine, $0.15 \mathrm{M}$ in the same buffer). A blank without enzyme solution was also prepared. The reaction was monitored for $3 \mathrm{~min}$ at $295 \mathrm{~nm}$ and velocity (Vo) was recorded. Phosphate buffer was used as negative control (activity of the enzyme without extract solution). Allopurinol was used as positive control. The percentage of xanthine oxidase inhibition was calculated using the following equation:

Inhibition $(\%)=\left[\left(\mathrm{Vo}_{\text {control }} \mathrm{Vo}_{\text {sample }}\right) \times 100\right] / \mathrm{Vo}_{\text {control }}$
$\mathrm{Vo}_{\text {control }}$ is the activity of enzyme without macerate/fraction and $\mathrm{Vo}_{\text {sample }}$ is the nzyme activity in the presence of extract or allopurinol

\section{Lipoxygenase (LOX) inhibition assay}

The lipoxygenase inhibiting activity was assayed spectrophotometrically as described by Lyckander and Malterud (1992). Briefly $100 \mu \mathrm{l}$ of the enzyme solution (at the final concentration of $200 \mathrm{U} / \mathrm{ml})$ was prepared in boric acid buffer $(0.2 \mathrm{M}$; $\mathrm{pH}$ 9) and mixed with $25 \mu \mathrm{\mu l}$ of extract solution (1 $\mathrm{mg} / \mathrm{ml}$ in boric acid buffer) and then incubated at room temperature for $3 \mathrm{~min}$. Reaction was subsequently initiated by the addition of substrate solution (linoleic acid, 250 $\mu \mathrm{M})$, and the velocity was recorded for $2 \mathrm{~min}$ at $234 \mathrm{~nm}$. Negative control was prepared and contained $1 \%$ methanol solution without extract solution. Quercetin was used as positive control. The percentage of lipoxygenase inhibition was calculated according to the following equation:

Inhibition $(\%)=\left[\left(\mathrm{Vo}_{\text {control }} \mathrm{Vo}_{\text {simple }}\right) \times 100\right] / \mathrm{Vo}_{\text {control }}$

$\mathrm{Vo}_{\text {control }}$ is the activity of enzyme in absence of extract solution and $\mathrm{Vo}_{\text {simple }}$ is the activity of the enzyme in the presence of extract or quercetin.

\section{Statistical analysis}

All data are expressed as mean \pm standard error of mean (SEM). The level of statistical significance was determined by analysis of variance followed by Duncan's new multiple range test.

\section{RESULTS}

The hexane, chloroform and methanol extracts of the bark of $E$. polystachya was evaluated for antiinflammatory activity in experimental animal models. The methanol extract (PAM) exhibited significant $(p<0.05)$ anti-inflammatory activity in all assays, instead hexane and chloroform extracts showed no anti-inflammatory activity (the results are not presented here).

As shown in Table 1, the methanol extract showed maximum inhibition of $73.26 \%$ at the dose of $200 \mathrm{mg} / \mathrm{kg}$ after $4 \mathrm{~h}$ of drug treatment in carrageenan induced paw oedema, whereas the standard drug indomethacin and 
Table 2. Effect of the PAM extract on cotton-pellet induced granuloma in rats.

\begin{tabular}{lccc}
\hline Treatment & Dose $(\mathbf{m g} / \mathbf{k g})$ & Weight of cotton pellet & Percentage of inhibition \\
\hline Cotton-Pellet control & 0 & $48.4 \pm 2.8$ & - \\
PAM & 50 & $37.1 \pm 6.0$ & 23.3 \\
PAM & 100 & $30.5 \pm 24.7$ & $37.0^{\mathrm{b}}$ \\
PAM & 200 & $22.7 \pm 23.9$ & $53.19^{\mathrm{a}}$ \\
Indomethacin & 10 & $21.3 \pm 4.7$ & $56.0^{\mathrm{a}}$ \\
\hline
\end{tabular}

Values represent mean \pm SEM $(n=8)$. One way ANOVA followed by Dunnet's multiple comparison test. ${ }^{a} p<0.05,{ }^{b} p<0.01$, statistically significant relative to control.

Table 3. Inhibition of histamine-induced paw edema of rats by treatment of methanol Extract (PAM).

\begin{tabular}{ccccccc}
\hline Doses & \multicolumn{5}{c}{ Time (h) after histamine injection } \\
\cline { 2 - 6 } mg/kg & & $\mathbf{0}$ & $\mathbf{1}$ & $\mathbf{2}$ & $\mathbf{3}$ & $\mathbf{4}$ \\
\hline Control & 0 & $36.8 \pm 7.9$ & $27.5 \pm 6.9$ & $22.2 \pm 7.6$ & $17.5 \pm 5.6$ & $13.7 \pm 4.4$ \\
12.5 & 0 & $27.2 \pm 3.5(26)^{a}$ & $18.1 \pm 2.8(34)^{b}$ & $16.1 \pm 4.5(27)^{a}$ & $14.2 \pm 1.9(19)^{a}$ & $5.4 \pm 1.32(60)^{b}$ \\
25 & 0 & $25.0 \pm 6.1(32)^{a}$ & $17.1 \pm 2.7(38)^{b}$ & $15.2 \pm 3.8(31)^{b}$ & $10.3 \pm 4.7(41)^{a}$ & $4.8 \pm 0.78(64)^{a}$ \\
50 & 0 & $21.3 \pm 2.9(42)^{b}$ & $16.4 \pm 2.9(40)^{a}$ & $13.4 \pm 2.9(39)^{a}$ & $8.1 \pm 3.7(53)^{a}$ & $4.3 \pm 1.23(68)^{a}$ \\
100 & 0 & $19.3 \pm 4.7(47)^{b}$ & $15.3 \pm 5.2(44)^{a}$ & $12.1 \pm 4.6(45)^{b}$ & $5.8 \pm 2.4(66)^{a}$ & $3.9 \pm 0.76(71)^{a}$ \\
In 10 & 0 & $14.2 \pm 1.8(61)^{a}$ & $14.6 \pm 3.6(46)^{a}$ & $11.8 \pm 6.2(47)^{a}$ & $5.0 \pm 1.0(71)^{b}$ & $3.1 \pm 0.98(77)^{a}$ \\
\hline
\end{tabular}

PAM and the vehicle were i.p. injected $10 \mathrm{~min}$ prior to the induction. Reference drug was orally administered $1 \mathrm{~h}$ in advance. Values are the mean $\pm \mathrm{SEM}$ ( $\mathrm{n}=8$ ). $a p<0.05, b p<0.01$. Increase of paw volume $(\%)$. Indomethacin $(\operatorname{In})$.

Table 4. Effect of the PAM extract on edema of the ear and the activity of MPO.

\begin{tabular}{lccc}
\hline Group $(\mathbf{m g})$ & Ear edema $(\mathbf{m g})$ & Group $(\mathbf{m g})$ & MPO activity (UMPO/mg) \\
\hline Basal & $7.3 \pm 1.4$ & Basal & $0.001 \pm 0.0004$ \\
$\mathrm{CO}$ & $14.6 \pm 4.3$ & $\mathrm{CO}$ & $0.98 \pm 0.05$ \\
$\mathrm{CO}+1.25$ & $13.3 \pm 4.2$ & $\mathrm{CO}+5.0$ & $0.41 \pm 0.07^{\mathrm{ab}}$ \\
$\mathrm{CO}+2.5$ & $12.4 \pm 3.7$ & $\mathrm{CO}+$ Indo & $0.26 \pm 0.05^{\mathrm{ab}}$ \\
$\mathrm{CO}+5.0$ & $11.1 \pm 3.8^{\mathrm{a}}$ & - & - \\
$\mathrm{CO}+7.5$ & $10.0 \pm 1.4^{\mathrm{a}}$ & - & - \\
$\mathrm{CO}+$ Indo & $8.1 \pm 2.6^{\mathrm{ab}}$ & - & - \\
\hline
\end{tabular}

Indomethacin (Indo), $1 \mathrm{mg}$ which was administered topically, was used as the reference anti-inflammatory (positive control). Ears which received only an application of the vehicle (basal). Each column represents the mean weight of the ears \pm SEM, $6 \mathrm{~h}$ after application of the croton oil (CO) and the MPO-mediated activity \pm SEM, ${ }^{a} p<0.01$, compared to the control group (CO), ${ }^{b}<<0.05$, compared to the Indo group (ANOVA, Tukey's test).

diclofenac sodium showed 78.43 and $68.12 \%$ of inhibition, respectively.

In the chronic model (cotton pellets-induced granuloma) PAM at dose of $200 \mathrm{mg} / \mathrm{kg}$ and standard drug (indomethacin) showed decreased formation of granuloma tissue of 53.19 and $56.0 \%$, respectively (Table 2).

In histamine-induced rat paw edema, measurements were conducted at $0.5,1,2,3,4$ and $6 \mathrm{~h}$ after subcutaneous injection of histamine. As shown in Table 3 , the hind paw edema of rats rapidly decreased from $1 \mathrm{~h}$ onward after the injection. The left hind paws that were used as control showed no increase of paw.
Application of croton oil to the left ear of the mice induced a very evident inflammatory response by $6 \mathrm{~h}$. The weight of the ear doubled as compared to the right ear (basal, with no croton oil applied). PAM failed to inhibit the intensity of edema at a dose of $1.25 \mathrm{mg}$; however, at doses of 2.5, 5.0, and $7.5 \mathrm{mg}$, this extract significantly $(p<0.01)$ reduced the intensity of edema (Table 4).

MPO is an enzyme present in the intracellular granules of neutrophils, and can be used as a marker for the influx of polymorphonuclear leukocytes into inflamed tissues. Application of croton oil induced an increase in MPO activity on the order of 20 -fold, at $6 \mathrm{~h}$ after application of 
Table 5. Effect of the PAM extract on antiarthritic activity in Micobecterium tuberculosis induced arthritis in rat.

\begin{tabular}{lc}
\hline Doses $(\mathbf{m g} / \mathbf{k g})$ & Oedema (mean $\pm \mathbf{m m})$ \\
\hline Control & $1.03 \pm 0.02$ \\
1 & $0.90 \pm 0.05$ \\
2 & $0.74 \pm 0.08^{a b}$ \\
4 & $0.60 \pm 0.06^{a b}$ \\
Prednisolone 5 & $0.52 \pm 0.04^{a}$ \\
\hline
\end{tabular}

${ }^{a} p<0.01$, compared to the control group, ${ }^{b} p<0.05$, compared to the Prednisolone group (ANOVA, Tukey's test).

Table 6. Effect of the PAM extract on TNF $\alpha$, IL-1 $\beta, \mathrm{PGE}_{2}$ and $\mathrm{LTB}_{4}$ in arthritis induced rat.

\begin{tabular}{ccccc}
\hline Doses $(\mathbf{m g} / \mathbf{k g})$ & TNFa $(\mathbf{p g} / \mathbf{m l})$ & $\mathrm{IL}-1 \boldsymbol{\beta}(\mathbf{p g} / \mathbf{m l})$ & PGE $_{2}(\mathbf{p g} / \mathbf{m l})$ & LTB $_{4}(\mathbf{p g} / \mathbf{m l})$ \\
\hline Control & 4500 & 1980 & 701 & 470 \\
1 & $3100^{\mathrm{a}}$ & $1488^{\mathrm{a}}$ & $531^{\mathrm{b}}$ & 402 \\
2 & $2200^{\mathrm{a}}$ & $975^{\mathrm{b}}$ & $419^{\mathrm{a}}$ & 358 \\
4 & $2000^{\mathrm{b}}$ & $769^{\mathrm{b}}$ & $263^{\mathrm{a}}$ & $268^{\mathrm{a}}$ \\
Prednisolone 5 & $1007^{\mathrm{b}}$ & $526^{\mathrm{b}}$ & $143^{\mathrm{b}}$ & $161^{\mathrm{b}}$ \\
\hline
\end{tabular}

Table 7. Inhibitory activities PAM against lipoxygenase (LOX) and xanthine oxidase (XO).

\begin{tabular}{lcc}
\hline Treatment & LOX & XO \\
\hline PAM & $46.1 \pm 3.29$ & $67.17 \pm 4.19$ \\
Allopurinol & ND & $75.32 \pm 5.84$ \\
Quercetin & $54.21 \pm 6.43$ & $71.50 \pm 5.16$ \\
\hline
\end{tabular}

Values are the mean \pm SEM $(n=6) .{ }^{a} p<0.01,{ }^{b} p<0.05$, Student's t-test. Showing significant inhibition of TNFa, IL-1 $1, \mathrm{PGE}_{2}$ parameters at higher dose levels of 2 and $4 \mathrm{mg} / \mathrm{kg}$. Expression of $\mathrm{LTB}_{4}$ was also inhibited but was not very significant statistically compared with prednisolone.

the stimulus. PAM extract $(5.0 \mathrm{mg})$ and indomethacin $(1.0$ $\mathrm{mg}$ ) significantly inhibited the activity of the enzyme. These results are as shown in Table 3. PAM showed statistically significant dose related inhibition of oedema in the injected paw with a maximum effect at dose levels of 2 and $4 \mathrm{mg} / \mathrm{kg}$ orally (Table 5). The PAM administered groups also did not show significant swelling in the uninjected paw (secondary response) of the experimental animals when compared with the vehicle control group.

Antiarthritic activity of PAM in M. tuberculosis induced inflammatory arthritis in mice (injected paw) is as shown in Table 6. At dose of $4 \mathrm{mg} / \mathrm{kg}$ (p.o.), PAM significantly decreased TNF $\alpha$, IL-1 $\beta$, PGE2 and LTB4 levels.

The activity of the extracts from $E$. polystachya against $\mathrm{XO}$ and LOX, were evaluated and the results are summarized as shown in Table 7 . The data indicated that PAM possesses strong activity in XO and LOX enzyme inhibition compared to that produced by allopurinol and quercetin.

\section{DISCUSSION}

In this investigation, PAM has been demonstrated to have anti-inflammatory effect at the dosages of 50,100 and $200 \mathrm{mg} / \mathrm{kg}$ on the carrageenan-induced paw edema in rats. Carrageenan induced oedema is commonly used as an experimental animal model for acute inflammation and the time course of edema development in carrageenan induced paw edema in rats is generally represented by a biphasic curve (Gepdiremen et al., 2004), of which the first phase occurs within $1 \mathrm{~h}$ of injection and it is mediated by the release of histamine and $5-\mathrm{HT}$ induced hind paw edema. Prostaglandins play a major role in the development of the second phase which is measured at 3 $\mathrm{h}$ time, which indicates that the methanolic extract exhibits its anti-inflammatory action by means of either inhibiting the synthesis, release or action of inflammatory mediators, namely, histamine, serotonin and prostaglandins might be involved in inflammation in the 
later phase.

In the current study, the anti-inflammatory effect of PAM was further evaluated in the histamine-induced paw edema in rats. Histamine is a potent mediator to act in acute inflammation; it is produced in the early phase of acute inflammation to increase vascular permeability. Since the action of histamine is transient, the inflammation decreases very quickly after induction. Hence, the early inflammatory response appears to be mediated mainly by histamine. In our study, PAM showed strong and dose-dependent inhibition on the paw edema in the early phase of the inflammation, implying that PAM exert the anti-inflammatory effect by acting on the early phase of the inflammation.

Chronic inflammation is a reaction arising when the acute response is insufficient to eliminate proinflammatory agents. Chronic inflammation includes a proliferation of fibroblasts and the infiltration of neutrophils and exudation (Dunne, 1990). Chronic inflammation occurs by means of the development of proliferative cells. These cells can be either spread or in granuloma form. PAM showed significant anti-inflammatory activity in cottonpellet induced granuloma and thus found to be effective in chronic inflammatory conditions, which reflected its efficacy in inhibiting the increase in the number of fibroblasts and synthesis of collagen and mucopoly-saccharides during granuloma tissue formation (Recio et al., 1995).

PAM showed significant $(p<0.05)$ activity on edema of the ear induced by local application of croton oil which involves the activation of phospholipase $\mathrm{A}_{2}$ and, consequently, biosynthesis of prostaglandins and leucotriens (Rotelli et al., 2003).

PAM possess significantly dose-related antiarthritic activity in $M$. tuberculosis-induced adjuvant arthritis test in rat, which is considered the close to simulating human rheumatoid arthritis. The appearance of secondary lesions (uninjected paw swelling) is the manifestation of cell mediated immunity ( $T$ cell response) and the suppression of this response by PAM suggests it to have immunosuppressive activity (Luster et al., 1982).

PAM significantly inhibited the expression of TNF- $\alpha$, $\mathrm{LTB}_{4}$ and IL-1 $\beta$ 1evels which are potent triggers involved in leukocyte migration (Crofford el al., 1997) in arthritic animal and this was also evident in the inhibition of cell migration and the exudate volume by decreasing the influx of leucocytes. TNF- $\alpha$, a key proinflammatory mediator of this activated immune network, connects other ancillary cells in the process of activation with a detrimental outcome (Aggarwal and Gutterman, 1992). $\mathrm{PGE}_{2}$ is another polypeptide mediator, activates lymphocytes and induces several components of the host's acute-phase response to infection and injury (Schrader and Thompson, 1994).

LOX and XO representing the key enzymes in the biosynthesis of leukotrienes that have been postulated to play an important role in the pathophysiology of several inflammatory and allergic diseases. Leukotrienes function as initiators of inflammation and their inhibition is considered to be partly responsible for the anti-inflammatory activity (Ammon et al., 1992). In the present study, PAM showed good anti-LOX and anti-XO activities. The inhibition percentage by PAM on $\mathrm{XO}$ is comparable to that allopurinol, is a therapeutic drug used to treat gout, which also suffers from many side effects such as hypersensitivity syndrome. Thus, there is a need to develop compounds with XO activity which is devoid of the undesirable side effects of allopurinol. Flavonoids and polyphenolic crude extracts have been reported to possess xanthine oxidase and lipoxygenase inhibitory activities (Halliwill, 1996). The high antioxidant capacity of PAM may be due to the presence of flavonoids or polyphenols in the extract (Perez and Baez, 2014).

The results of this study demonstrated that methanol extract of the bark of $E$. polystachya acts as an antiinflammatory agent. It also can be a good source of effective crude inhibitors for XO and LOX. The finding presented in this study are encouraging and substanciate the search for newer pharmacophores in palo azul behind the anti-inflammatory effect.

\section{Conflict of interest}

Authors declare that there are no conflicts of interest.

\section{REFERENCES}

Alvarez L, Rios MY, Esquivel C, Chavez MI, Delgado G, Aguilar MI (1999). Cytotoxic isoflavans from Eysenhardtia polystachya. J. Nat. Prod. 61:767-770.

Alvarez L, Delgado G (1999a). C- and O-Glycosyl-cxhydroxydihydrochalcones from Eysenhardtia polystachya. Phytochemistry 50:681-687.

Aggarwal BB, Gutterman JU (1992). Tumor necrosis factor. Human Cvtokines. Blackwell Scientific Publications: Boston, MA, USA.

Ammon HPT, Annazodo MI, Safayhi H, Dhawan BN, Scrimal R (1992). Curcumin: a potent inhibitor of leukotriene B4 formation in rat peritoneal polymorphonuclear neutrophils (PMNL). Planta Med. 58:226-229.

Arrigoni-Martelli E, Bramm E (1975). Investigations in the influence of cyclophosphamide gold sodium thiomalate and D-penicillamine on nystatin oedema and adjuvant arthritis. Agents Actions 5:264267.

Bradley PP, Priebat DA, Chiristensen RD, Rothstein G (1982). Measurement of cutaneous inflammation: estimation of neutrophil content with an enzyme marker. J. Investig. Dermatol. 78:206-209.

Burns DT, Dalgarno BG, Ggargan P, Grimshaw J (1984). An isoflavone and a coumestan from Eysenhardtia polystachya-robert boyle's fluorescent acid-base indicator. Phytochemistry 3:167-169.

Chimenti F, Fioravanti R, Bolasco A, Chimenti P, Secci D, Rossi F, Yáñez M (2009). Chalcones: A valid scaffold for monoamine oxidases inhibitors. J. Med. Chem. 52:2818-2824.

Crofford LJ, Tan B, McCarthy CJ, Hia T (1997). Involvement of nuclear factor Kappa $B$ in the regulation of ciclooxygenase-2 expression by interlukin-1 in rheumatoid synoviocytes. Arthitis Rheum. 40:226-236.

Dunne MW (1990). Pathophysiology: Concepts of Altered Health States with Contributors,' ed. by Porth C. M., Lippincott, Philadelphia. pp. 165-176.

Gepdiremen A, Mshvildadze V, Suleyman H, Elias R (2004). Acute and chronic anti-inflammatory effects of Hedera cochica in rats, J. Ethnopharmacol. 94:191-195.

Gupta M, Mazumdar UK, Sivakumar T, Laxmi MV, Somalingappa SK, 
Sambathkumar R, Manikandan L (2003). Evaluation of antiinflammatory activity of chloroform Extract of Bryonia laciniosa in experimental animal models. Biol. Pharm. Bull. 26:1342-1344.

Jing-Rong W, Hua Z, Zhi-Hong JG, Yuen FWG, Liang L (2008). In vivo anti-inflammnatory and analgesic activities of a purified saponin fraction derived from the root of llex pubescens. Biol. Pharm. Bull. 31:643-650.

Halliwill B (1996). Antioxidants in human health and diseases. Ann. Rev. Nutr. 16:33-50.

Luster ML, Dean JH, Boorman GA (1982). A cell mediated S immunity and its application in toxicology. En vivo Health Perspect. 43:31-36.

Lyckander IM, Malterud KE (1992). Lipophilic flavonoids from Orthosiphon spicatus as inhibitors of 15-lipoxygenase. Acta Pharm. Nordica. 4:159-166.

Narvaez-Mastache JM, Novillo F, Delgado G (2008). Antioxidant arylprenylcoumarin, flavan-3-ols and flavonoids from Eysenhardtia subcoriacea. Phytochemistry. 69: 451-456.

Owen PL, Timothy J (1999). Xanthine oxidase inhibitory activity of northeastern North American plant remedies used for gout. J. Ethnopharmacol. 64:149-160.
Perez RMG, Vargas R, Perez GS, Zavala S (1998). Antiurolithiatic activity of Eysenhardtia polystachya aqueous extract on ratsPhytoter. Res. 12:144-145.

Gutierrez RM, Baez EG (2014). Evaluation of hypoglycemic, antioxidant and antiglycating activities of the Eysenhardtia polystachya. Pharmcog. Mag. (Supplement 2)10:S404-S418.

Recio MC, Giner RM, Manez S, Ros JL (1995). Structural requirements for the anti-Inflammatory activity of natural triterpenoids. Planta Med. 61:182-185.

Rotelli AE, Guardia T, Juárez AO, De La Rocha NE, Pelzer LE (2003) Comparative study of flavonoids in experimental models of inflammation. Pharmacol. Res. 48:601-606.

Schrader JW, Thompson AW (1994). The cytokine Hanbook, $2^{\text {nd }}$ edn. Academic Press: London UK.

Van Arman CG (1974). Anti-inflammatory drugs. Clin. Pharm. Ther. 16:900-904

Washiyama M. Sasaki, Y, Hosokawa T, Nagumo S (2009). Antiinflammatory constituents of Sappan lignum. Biol. Pharm. Bull. 32:941-944. 